\title{
Bimetallic phthalocyanine heterostructure used for highly selective electrocatalytic $\mathrm{CO}_{2}$ reduction
}

\author{
Chenhuai Yang ${ }^{1 \dagger}$, Zengqiang $\mathrm{Gao}^{1 \dagger}$, Dingjia Wang ${ }^{2 \dagger}$, Shuyu $\mathrm{Li}^{1}$, Junjun $\mathrm{Li}^{1}$, Yating $\mathrm{Zhu}^{1}$, Haiqing Wang ${ }^{3}$, \\ Wenjuan Yang ${ }^{4}$, Xuejiao J. Gao ${ }^{2^{*}}$, Zhicheng Zhang ${ }^{1 *}$ and Wenping $\mathrm{Hu}^{1}$
}

\begin{abstract}
Heterogeneous molecular catalysts, such as metal phthalocyanines, are efficient electrocatalysts for $\mathrm{CO}_{2}$ reduction reaction $\left(\mathrm{CO}_{2} \mathrm{RR}\right)$. However, the rational design and synthesis of a molecular catalyst-based heterostructure for $\mathrm{CO}_{2} \mathrm{RR}$ remains challenging. Herein, we developed a crystalline bimetallic phthalocyanine heterostructure electrocatalyst $(\mathrm{CoPc} / \mathrm{FePc} \mathrm{HS})$, which achieved an excellent $\mathrm{CO}_{2}$-to-CO conversion efficiency (99\%) and outstanding long-term stability after $10 \mathrm{~h}$ of electrocatalysis. Density functional theory calculations revealed that the enhancement of $\mathrm{CO}_{2} \mathrm{RR}$ performance could be attributed to the distinct electron transfer pattern between FePc and CoPc. The heterostructural engineering in molecular catalysts would inspire a unique approach for improving $\mathrm{CO}_{2} \mathrm{RR}$ performance.
\end{abstract}

Keywords: molecular catalyst, phthalocyanine heterostructure, $\mathrm{CO}_{2}$ reduction, electronic effect

\section{INTRODUCTION}

Due to the consumption of fossil fuels after the industrial revolution, the concentration of ambient $\mathrm{CO}_{2}$ has significantly increased, leading to several concerns such as global warming and abnormal global climate [1-3]. The increasing concern regarding $\mathrm{CO}_{2}$ content in the atmosphere pushed governments to increase their investment to address the $\mathrm{CO}_{2}$ issue and encouraged numerous researchers to explore this field using different technologies that enabled the effective, safe, and sustainable utilization of $\mathrm{CO}_{2}$ [4-6]. Unlike the thermal catalysis operated at high temperatures, the electrochemical reduction is an ideal and attractive approach for creating a carbon-neutral energy cycle, which can transform into the sustainable production and regeneration of carbon-based value-added chemicals and fuels by harvesting intermittent electricity from renewable energy sources [7-10]. However, activating $\mathrm{CO}_{2}$ is difficult because of the multiple electrons and proton transfer involved in electrocatalysis; therefore, new high-performance electrocatalysts that can enhance sluggish reaction kinetics must be exploited to overcome the massive energy barrier resulting from the excessive chemical inertness of molecules and the related multielectron transfer methods [11-13].

Although noble-metal catalysts ( $\mathrm{Au}, \mathrm{Ag}$, etc.) exhibit competitive activity, their depletable resource and high price considerably hinder their general and widespread applications in the energy field [14-16]. Considering their large specific surface area and good electrical conductivity, atomically dispersed transition metals embedded in nitrogen-doped carbon supports are attractive for $\mathrm{CO}_{2}$ reduction reaction $\left(\mathrm{CO}_{2} \mathrm{RR}\right)$, but precisely regulating the topography of the catalytic sites is difficult [17-19]. Molecular catalysts, which combine transition-metal elements such as $\mathrm{Co}, \mathrm{Ru}, \mathrm{Fe}, \mathrm{Ni}$, and $\mathrm{Cu}$ with organic ligands such as phthalocyanine, polypyridine, porphyrin, and other macrocyclic structures, contain well-defined active sites and uniform and tunable structures, contributing to investigating catalytic mechanisms for the electrochemical reduction of $\mathrm{CO}_{2}$ [20-24]. Metal phthalocyanines (MPcs) used as dyes have been recently studied to convert $\mathrm{CO}_{2}$ to $\mathrm{CO}$ because of their low cost and stable structure, and they exhibit high catalytic activity $[25,26]$. The natural $\mathrm{M}-\mathrm{N}_{4}$ molecular structure (one metal center, four coordinated nitrogen atoms) can effectively adjust the binding ability of the metal center to key intermediates and facilitate the rapid transfer of electrons [27-35].

Some studies have reported that the electron-withdrawing or electron-donating group is externally attached to the macrocyclic structure of $\mathrm{M}-\mathrm{N}_{4}$ to change the electron cloud density around the metal center, thereby changing the binding energy of the key intermediate $\mathrm{CO}$ and improving the selectivity of the reaction. For example, CoPc with pyridine moieties (CoPc-Pyr) supported on a carbon electrode has been recently synthesized, and the Faradaic efficiency $(\mathrm{FE})$ of $\mathrm{CO}\left(\mathrm{FE}_{\mathrm{CO}}\right)$ reached $90 \%$ with a partial CO current density of $2.5 \mathrm{~mA} \mathrm{~cm}^{-2}$ [36]. Wang et al. [37] synthesized CoPc with cyano groups (CoPc-CN) for $\mathrm{CO}_{2}-$ to-CO conversion and achieved an FE of $95 \%$. Because of the difference in electron cloud density around different metal centers, the possible synergistic effect of MPcs with different metal centers is beneficial to changing the electron cloud density around the metal center, which consequently changes the binding energy of $\mathrm{CO}$ and improves the selectivity of reaction

\footnotetext{
${ }^{1}$ Tianjin Key Laboratory of Molecular Optoelectronic Sciences, Department of Chemistry, School of Science, Tianjin University, Tianjin 300072, China

${ }^{2}$ College of Chemistry and Chemical Engineering, Jiangxi Normal University, Nanchang 330022, China

${ }^{3}$ Collaborative Innovation Center of Technology and Equipment for Biological Diagnosis and Therapy in Universities of Shandong, Institute for Advanced Interdisciplinary Research (iAIR), University of Jinan, Jinan 250022, China

${ }^{4}$ SZU-NUS Collaborative Innovation Centre for Optoelectronic Science \& Technology, International Collaborative Laboratory of 2D Materials for Optoelectronics Science and Technology of Ministry of Education, Institute of Microscale Optoelectronics, Shenzhen University, Shenzhen 518060, China

$\dagger$ These authors contributed equally to this work.

* Corresponding authors (emails: zczhang19@tju.edu.cn (Zhang Z); gaoxj@jxnu.edu.cn (Gao XJ))
} 
products. However, the synergistic effect between MPcs with different metal centers for $\mathrm{CO}_{2} \mathrm{RR}$ remains unclear. In this work, the crystalline cobalt/iron bimetallic phthalocyanine heterostructure $(\mathrm{CoPc} / \mathrm{FePc} \mathrm{HS})$ was synthesized via the solvothermal treatment, in which $\mathrm{FePc}$ was distributed in the two ends, and $\mathrm{CoPc}$ was concentrated in the middle of the HS.

The obtained $\mathrm{CoPc} / \mathrm{FePc}$ HS could efficiently enhance the electrocatalytic performance of $\mathrm{CO}_{2} \mathrm{RR}$ because of the strong coupling effect between $\mathrm{CoPc}$ and FePc. It can also rationally regulate $\mathrm{CO}_{2}$ reduction selectivity toward $\mathrm{CO}$ by adjusting the ratio of $\mathrm{CoPc} / \mathrm{FePc}$ in the HS. The $\mathrm{CoPc} / \mathrm{FePc}$ HSs exhibit prominent performance with a high $\mathrm{FE}$ of $99.2 \%$ and an outstanding CO partial current density of $15.9 \mathrm{~mA} \mathrm{~cm}^{-2}$ at the potential of $-0.87 \mathrm{~V}$ versus reversible hydrogen electrode (RHE) in a near-neutral aqueous solution, which can considerably suppress the competitive hydrogen evolution reaction (HER). Density functional theory (DFT) calculations reveal that the formation of intermediate $* \mathrm{COOH}$ is the rate-determining step for $\mathrm{CO}_{2}$-to-CO conversion, and $\mathrm{CoPc}$ is regarded as the dominating active center. The enhancement of $\mathrm{CO}_{2} \mathrm{RR}$ performance could be attributed to the moderate adsorption of reaction intermediates at the HS between $\mathrm{FePc}$ and $\mathrm{CoPc}$ induced by the distinct electron transfer.

\section{EXPERIMENTAL SECTION}

\section{Materials}

$\mathrm{CoPc}(95 \%)$ and $\mathrm{FePc}(97 \%)$ were purchased from TCI. Potassium bicarbonate $\left(\mathrm{KHCO}_{3}\right), \mathrm{N}, \mathrm{N}$-dimethylformamide (DMF, 99.7\%), ethanol $\left(\mathrm{C}_{2} \mathrm{H}_{5} \mathrm{OH}, 99.5 \%\right)$, and isopropyl alcohol $\left(\mathrm{C}_{3} \mathrm{H}_{8} \mathrm{O}, 99.5 \%\right)$ were purchased from Aladdin. Ketjen black carbon and $5 \mathrm{wt} \%$ Nafion solution were purchased from the Fuel Cell Store. All chemicals were used without further purification.

\section{Characterization}

Scanning electron microscopy (SEM) measurements were performed using an SU8010 microscope. High-resolution transmission electron microscopy (HRTEM), high-angle annular dark-field scanning transmission electron microscopy (HAADFSTEM), and energy dispersive spectroscopy (EDS) elemental mapping were performed using an FEI Talos F200X G2 microscope operated at $200 \mathrm{kV}$. Powder X-ray diffraction (PXRD) patterns were analyzed using a Rigaku SmartLab 9 KW with $\mathrm{Cu} \mathrm{Ka}$ radiation $(\lambda=1.542 \AA)$ operating at $45 \mathrm{kV}$ and $200 \mathrm{~mA}$. X-ray photoelectron spectroscopy (XPS) was performed on an ESCALAB-250Xi spectrometer (Thermo Fisher Scientific) using $\mathrm{Al} \mathrm{Ka}$ radiation. Fourier transform infrared (FTIR) spectra were collected using a Bruker Vertex 70 FTIR spectrometer. Thermogravimetric analysis (TGA) was conducted using a Mettler Toledo TGA 2 thermal analysis system. Raman measurements were conducted using DXR2xi (Thermo Fisher Scientific, CN) with $532 \mathrm{~nm}$ as the excitation wavelength. The solidstate absorption spectra were collected using a Shimadzu UV3600 spectrophotometer.

\section{$\mathrm{CoPc} / \mathrm{FePc} \mathrm{HS}$ synthesis}

$\mathrm{CoPc} / \mathrm{FePc} \mathrm{HS}$ with different $\mathrm{Co} / \mathrm{Fe}$ molar ratios (3:1, 1:1, 1:3), $\mathrm{CoPc}, \mathrm{FePc}$, were elaborately prepared [38]. First, a 200-mg mixture of $\mathrm{CoPc}$ and $\mathrm{FePc}$ was dispersed into $70 \mathrm{~mL}$ of DMF and sonicated for $60 \mathrm{~min}$ to obtain a homogeneous solution. Then, the solution was transferred into a $100-\mathrm{mL}$ Teflon-lined solvothermal autoclave and heated in an oven at $180^{\circ} \mathrm{C}$ for $24 \mathrm{~h}$. After cooling down to room temperature, the purple microrodshaped precipitates in the solution were collected, washed with ethanol thrice, centrifuged, and dried at $60^{\circ} \mathrm{C}$ for $4 \mathrm{~h}$. Finally, the prepared precipitates were calcined in the furnace at $450^{\circ} \mathrm{C}$ for $3 \mathrm{~h}$ to obtain $\mathrm{CoPc} / \mathrm{FePc} \mathrm{HS}$. The high-purity $\operatorname{Ar}(99.999 \%)$ was used as the carrier gas with a flow rate of $220 \mathrm{sccm}$.

\section{Working electrode preparation}

$\mathrm{CoPc} / \mathrm{FePc} \mathrm{HS}(1 \mathrm{mg})$ and Ketjen black carbon $(1 \mathrm{mg})$ were dispersed into a mixture of $320 \mu \mathrm{L}$ isopropyl alcohol, $60 \mu \mathrm{L}$ deionized water, and $20 \mu \mathrm{L}$ commercial $5 \mathrm{wt} \%$ Nafion solution and sonicated for $40 \mathrm{~min}$ to yield a homogeneous ink. Subsequently, $100 \mu \mathrm{L}$ of the ink was uniformly coated on a Sigracet 29 BC GDL $(1 \mathrm{~cm} \times 1 \mathrm{~cm})$ to prepare a composite with a loading density of $0.25 \mathrm{mg} \mathrm{cm}^{-2}$. The coated carbon paper was dried overnight at ambient temperature and pressure.

\section{Electrochemical measurement}

All electrochemical measurements were performed in a threeelectrode system with a sealed two-compartment H-type cell separated by a Nafion-117 proton exchange membrane. Each compartment was filled with $40 \mathrm{~mL} \mathrm{KHCO}_{3}$ solution with a concentration of $0.5 \mathrm{~mol} \mathrm{~L}^{-1}$. A saturated $\mathrm{Ag} / \mathrm{AgCl}$ and a platinum plate $\left(1.5 \times 1.5 \mathrm{~cm}^{2}\right)$ were used as the reference and counter electrodes, respectively. The testing potential can be converted to the RHE using the formula $E_{\mathrm{RHE}}=E_{\mathrm{Ag} / \mathrm{AgCl}}+E_{\mathrm{Ag} / \mathrm{AgCl}}^{\theta}+0.0592 \times$ $\mathrm{pH}$. Electrochemical measurements were performed using a CHI760E workstation. Prior to the measurements, the electrolyte was thoroughly degassed by purging with $\mathrm{CO}_{2}$ (99.999\%) for $30 \mathrm{~min}$ with a flow rate of $20 \mathrm{sccm}$. The catholyte was stirred at a speed of $500 \mathrm{rpm}$, and its $\mathrm{pH}$ was measured to be 7.4. Cyclic voltammetry $(\mathrm{CV})$ was performed 20 times in the potential range of 0.03 to $-1.37 \mathrm{~V}$ ( $v s$. RHE) at a scan rate of $100 \mathrm{mV} \mathrm{s}^{-1}$ to activate the working electrode and remove adsorbed gases. Linear sweep voltammetry (LSV) was performed in the same potential range with $\mathrm{CV}$ at a scan rate of $5 \mathrm{mV} \mathrm{s}^{-1}$. The chronoamperometry (CA) was measured at different fixed potentials to evaluate the $\mathrm{CO}_{2} \mathrm{RR}$ performance. Gas products were analyzed using a gas chromatograph (GC7900, Tianmei) equipped with a thermal conductivity detector for $\mathrm{H}_{2} / \mathrm{CO}$ analysis and with a flame ionization detector for hydrocarbon analysis. The FE of gas products was calculated using the equation $\mathrm{FE}(\%)=n F c V / Q$ $\times 100$, where $n$ is the number of transferred electrons of $\mathrm{CO}_{2} \mathrm{RR}$ or HER, $F$ is the Faraday constant $\left(96,485 \mathrm{C} \mathrm{mol}^{-1}\right), c$ is the volume ratio of gas products, $V$ is the total molar flow rate of gas, and $Q$ is the total consumed charge in electrolysis.

\section{Computational details}

The geometric optimizations and projected density of states (PDOS) calculations were performed using Vienna ab-initio Simulation Package [39]. Projector-augmented wave [40] pseudopotentials with Perdew-Burke-Ernzerhof [41] exchange-correlation functional were used. Standard Monkhorst-Pack grid [42] samplings were employed at $3 \times 3 \times 3$ and $7 \times 7 \times 7$ for the geometric optimizations and PDOS analyses, respectively. The energy cutoff was set to $500 \mathrm{eV}$, and the convergence thresholds for the electronic structure and forces were set to $10^{-5} \mathrm{eV}$ and $0.02 \mathrm{eV} \AA^{-1}$, respectively. The Hubbard $U_{\text {eff }}=3.0$, which was used in previous phthalocyanine metal complex calculations [43], was used to correct the strong Coulombic interactions of $d$ 
electrons for Fe and Co. The van der Waals (vdW) corrections were estimated in the DFT-D3BJ form [44].

The free energy diagrams of $\mathrm{CO}_{2} \mathrm{RR}$ were estimated using the Nørskov equation,

$\Delta G=\Delta E+\Delta \mathrm{ZP} E-T \Delta S+\Delta G_{U}+\Delta G_{\mathrm{pH}}+\Delta G_{\text {field }}$,

where $\Delta E, \Delta \mathrm{ZPE}$, and $\Delta S$ are the total energy, zero-point energy, and entropy difference of the products and reactants, respectively; $T$ is the temperature (considered as $298.15 \mathrm{~K}) ;(\Delta E+$ $\triangle \mathrm{ZP} E-T \Delta S$ ) is the Gibbs free energy difference, which can be directly obtained using DFT calculations; $\Delta G_{U}$ is defined as $e U$ where $U$ and $e$ are the electrode potential with respect to standard hydrogen electrode and the charge transferred, respectively; $\Delta G_{\mathrm{pH}}=2.303 k_{\mathrm{B}} T \times \mathrm{pH}$, where $k_{\mathrm{B}}$ is the Boltzmann constant and the $\mathrm{pH}$ is 7.4 in the present work; $\Delta G_{\text {field }}$ is the free energy correction resulting from the electrochemical double layer and is neglected in the present study considering the previous studies [45]. The free energy of CO was not calculated via DFT simulation, but was obtained from the known free energy change of the reaction $\mathrm{CO}_{2}(\mathrm{~g})+\mathrm{H}_{2}(\mathrm{~g})=\mathrm{CO}(\mathrm{g})+\mathrm{H}_{2} \mathrm{O}$ (l) under the standard condition, i.e., $0.22 \mathrm{eV}$. The $\mathrm{CO}_{2} \mathrm{RR}$ involves two electron transfers, with a free energy correction of $0.43 \mathrm{eV}$ in each electronic transfer step. After the correction of $\Delta G_{\mathrm{pH}}$, the final $\Delta G=0.22+0.43 \times 2=1.08 \mathrm{eV}$.

\section{RESULTS AND DISCUSSION}

SEM characterization was performed to study the morphology and growth regulation of the prepared $\mathrm{CoPc} / \mathrm{FePc} \mathrm{HS}$ (Fig. 1b and Fig. S1). As the FePc content increased, the tips of the prepared microrods became sharper, and the length of the microrods increased accordingly. This result indicates that the mass ratio of $\mathrm{CoPc} / \mathrm{FePc}$ considerably affects the HS morphology. The PXRD patterns were applied to analyze the crystallinity of the prepared microrods (Fig. S2). The commercial CoPc and $\mathrm{FePc}$ exhibit poor crystallinity, but the prepared $\mathrm{CoPc}$ and $\mathrm{FePc}$ microrods become highly crystalline. After comparison with the standard card (JCPDS: 14-0948, JCPDS: 14-0926), CoPc and FePc can be assigned to $\beta$-phase $\mathrm{CoPc}$ and $\beta$-phase $\mathrm{FePc}$, respectively. The as-obtained $\mathrm{FePc} / \mathrm{CoPc} \mathrm{HS}$ also exhibits high crystallinity with strong diffraction peaks at $7.06^{\circ}, 9.25^{\circ}, 18.24^{\circ}$ and $18.66^{\circ}$, which correspond to the $\beta$ phase CoPc. TGA measurement indicates that the weight of $\mathrm{CoPc} / \mathrm{FePc} \mathrm{HS}$ changes slightly in the range of $0-600^{\circ} \mathrm{C}$, indicating that the HSs exhibit excellent stability in the subsequent annealing process (Fig. S3). UV-vis absorption spectra (Fig. S4) indicate that the characteristic peaks of $\mathrm{CoPc} / \mathrm{FePc} \mathrm{HS}$ overlap with those of $\mathrm{CoPc}$ and $\mathrm{FePc}$, confirming the existence of macrocycle structure in the HS. The characteristic peaks of $\mathrm{CoPc} / \mathrm{FePc} \mathrm{HS}$ at approximately 330 and $674 \mathrm{~nm}$ belong to $\mathrm{B}$ and Q bands, respectively [46]. When the CoPc/FePC HS is formed, the Q-band exhibits a slight red shift relative to $\mathrm{CoPc}$. FTIR and Raman spectra further confirm that the $\mathrm{CoPc} / \mathrm{FePc} \mathrm{HS}$ shows the characteristic peaks of $\mathrm{FePc}$ and $\mathrm{CoPc}$, indicating that the molecular structures of $\mathrm{FePc}$ and CoPc remain in the HS (Fig. S5). The Raman spectrum shows the stretching vibration of the macrocycle. $A_{1 g}$ symmetry of 592 and $834 \mathrm{~cm}^{-1}$ bands can be ascribed to benzene ring deformation, and $\mathrm{B}_{1 \mathrm{~g}}$ at 684 and $1542 \mathrm{~cm}^{-1}$ and $\mathrm{B}_{2 \mathrm{~g}}$ at $1498 \mathrm{~cm}^{-1}$ (macrocycle breathing) connect with pyrrole stretch. These regions correspond to heavy atom-nitrogen (M-nitrogen) inplane stretching and bending vibrations as well as displacements on the $\mathrm{C}-\mathrm{N}-\mathrm{C}$ bridge bond of the phthalocyanine molecule. The peak at $1338 \mathrm{~cm}^{-1}$ belongs to $\mathrm{C}-\mathrm{N}$ stretching vibration and that at $1537 \mathrm{~cm}^{-1}$ belongs to $\mathrm{C}=\mathrm{C}$ stretching vibration [47]. The characteristic peaks in the FTIR spectra at 731, 756, 780, and $1088 \mathrm{~cm}^{-1}$ in $\mathrm{CoPc} / \mathrm{FePc} \mathrm{HS}$ indicate the presence of $\beta$-phase, which is consistent with the conclusion obtained via XRD. The characteristic peak at $911 \mathrm{~cm}^{-1}$ in $\mathrm{CoPc} / \mathrm{FePc} \mathrm{HS}$ belongs to the metal-ligand vibration band, indicating the existence of the $\mathrm{M}$ $\mathrm{N}_{4}$ macrocycle structure [48-50]. The stable $\mathrm{M}-\mathrm{N}_{4}$ macrocycle structure in $\mathrm{CoPc} / \mathrm{FePc} \mathrm{HS}$ is expected to facilitate rapid electron transfer during catalysis [51-53]. TEM was performed to further

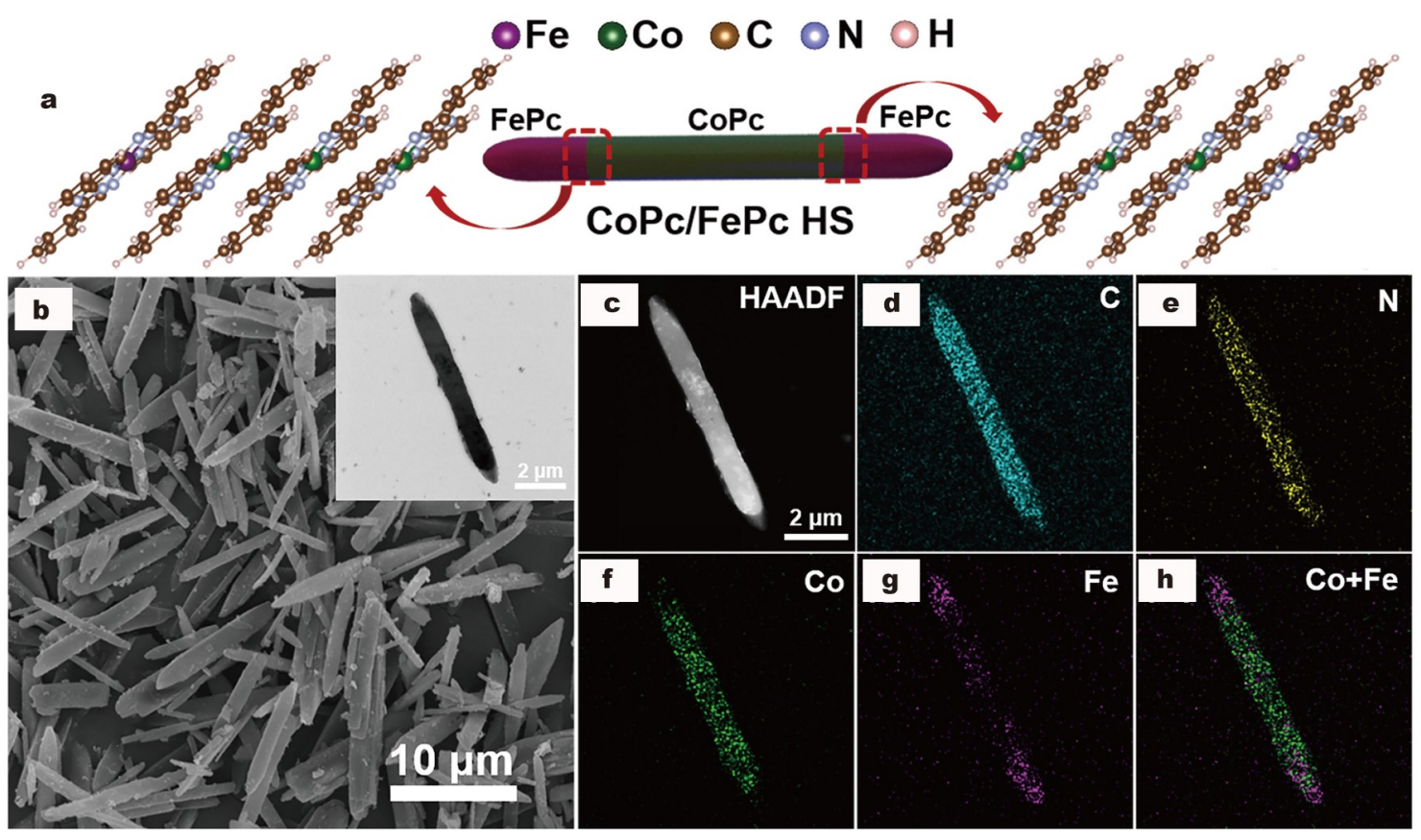

Figure 1 (a) Schematic of $\mathrm{CoPc} / \mathrm{FePc}$ HS. (b) SEM image of CoPc/FePc HS; the inset displays the TEM image of CoPc/FePc HS. (c-h) HAADF-STEM image and the corresponding overlaid EDS mappings of $\mathrm{CoPc} / \mathrm{FePc} \mathrm{HS}$. 
confirm the morphology and element distribution of $\mathrm{CoPc} / \mathrm{FePc}$ HS (inset in Fig 1b). HAADF-STEM image and the corresponding EDS maps indicate that the Co element is mainly enriched at the middle of the microrod, whereas the Fe element is distributed in the ends (Fig. 1c-h). Furthermore, the EDS spectrum shows that the $\mathrm{Co} / \mathrm{Fe}$ atomic fraction ratio in the microrod is consistent with the $\mathrm{CoPc} / \mathrm{FePc}$ feedstock ratio $(3: 1)$, as shown in Fig. S6. Considering the above characterizations, we speculate that the special structure of heterojunction is related to the nucleation and growth rate of $\mathrm{CoPc}$ and $\mathrm{FePc}$ during the solvothermal reaction. CoPc preferentially nucleates and crystallizes to form the body of the HS microrod. Then, because of the similar crystal structure of FePc and $\mathrm{CoPc}, \mathrm{FePc}$ crystallizes along $\mathrm{CoPc}$ to form the tips on both sides.

XPS tests were performed to study the surface elemental compositions and electronic structures of $\mathrm{CoPc} / \mathrm{FePc} \mathrm{HS}, \mathrm{FePc}$, and $\mathrm{CoPc}$ (Fig. S7) [54]. The $\mathrm{N}$ 1s spectrum of $\mathrm{CoPc} / \mathrm{FePc} \mathrm{HS}$ shows only one peak at $399.1 \mathrm{eV}$, which corresponds to the pyridinic $\mathrm{N}$ in the $\mathrm{M}-\mathrm{N}_{4}$ structure of phthalocyanine. The Co $2 \mathrm{p}$ spectrum of $\mathrm{CoPc} / \mathrm{FePc} \mathrm{HS}$ exhibits two peaks at 796.3 and $780.6 \mathrm{eV}$, corresponding to Co $2 \mathrm{p}_{1 / 2}$ and Co $2 \mathrm{p}_{3 / 2}$. Each peak is divided into two doubles, which can be ascribed to $\mathrm{Co}^{2+}$ and $\mathrm{Co}^{3+}$, respectively [55-57]. $\mathrm{Co}^{2+}$ is derived from the Co site in the CoPc part, and $\mathrm{Co}^{3+}$ is possibly derived from the oxidation of $\mathrm{Co}^{2+}[58,59]$. Compared with $\mathrm{CoPc}$, the slight shift of Co $2 \mathrm{p}$ in
$\mathrm{CoPc} / \mathrm{FePc} \mathrm{HS}$ to high binding energy confirms the change in the coordination environment of Co sites in $\mathrm{CoPc} / \mathrm{FePc} \mathrm{HS}$, which reduces the charge in the surface of $\mathrm{CoPc}$. The Fe $2 \mathrm{p}$ spectrum of $\mathrm{CoPc} / \mathrm{FePc} \mathrm{HS}$ also shows the valence states of $\mathrm{Fe}^{2+}$ and $\mathrm{Fe}^{3+}$. The $\mathrm{Fe} 2 \mathrm{p}$ in $\mathrm{CoPc} / \mathrm{FePc} \mathrm{HS}$ shifts to low binding energy, indicating an increased local electron density of the $\mathrm{Fe}$ site in $\mathrm{CoPc} / \mathrm{FePc} \mathrm{HS}$ [60-62]. Notably, the inhomogeneous $\mathrm{Co} /$ Fe elemental distribution causes an electronic effect between Co and Fe species, which might bring the unexpected electrical property of $\mathrm{CoPc} / \mathrm{FePc} \mathrm{HS}$.

The catalytic activity of $\mathrm{CoPc} / \mathrm{FePc} \mathrm{HS}$ for electrochemical $\mathrm{CO}_{2}$ reduction was investigated in a saturated $0.5 \mathrm{~mol} \mathrm{~L} \mathrm{~L}^{-1}$ $\mathrm{KHCO}_{3}$ solution using a sealed three-electrode $\mathrm{H}$-type cell. The as-prepared $\mathrm{CoPc} / \mathrm{FePc} \mathrm{HS}$ and Vulcan XC-72R carbon black were ultrasonically mixed with $5 \mathrm{wt} \%$ Nafion solution in isopropyl alcohol and deionized water, and the resulting homogeneous paste was coated onto Sigracet 29 BC GDL to prepare the working electrode. The electrodes containing $\mathrm{CoPc}$ and $\mathrm{FePc}$ were prepared similarly (Fig. S8). In the LSV test, the CoPc/FePc $\mathrm{HS}(\mathrm{Co} / \mathrm{Fe}$ ratio of $3: 1)$ exhibits a steep increase in current density at the potential of $-0.32 \mathrm{~V} v s$. RHE, indicating that $\mathrm{CO}_{2}$ is successfully reduced on $\mathrm{CoPc} / \mathrm{FePc} \mathrm{HS}$ (Fig. 2a). The geometric current density of $\mathrm{CoPc} / \mathrm{FePc} \mathrm{HS}$ reaches up to $37.86 \mathrm{~mA} \mathrm{~cm}^{-2}$ at $-1.17 \mathrm{~V}$ vs. RHE, whereas $\mathrm{CoPc}$ and $\mathrm{FePc}$ exhibit low current densities of 27.69 and $18.69 \mathrm{~mA} \mathrm{~cm}^{-2}$,
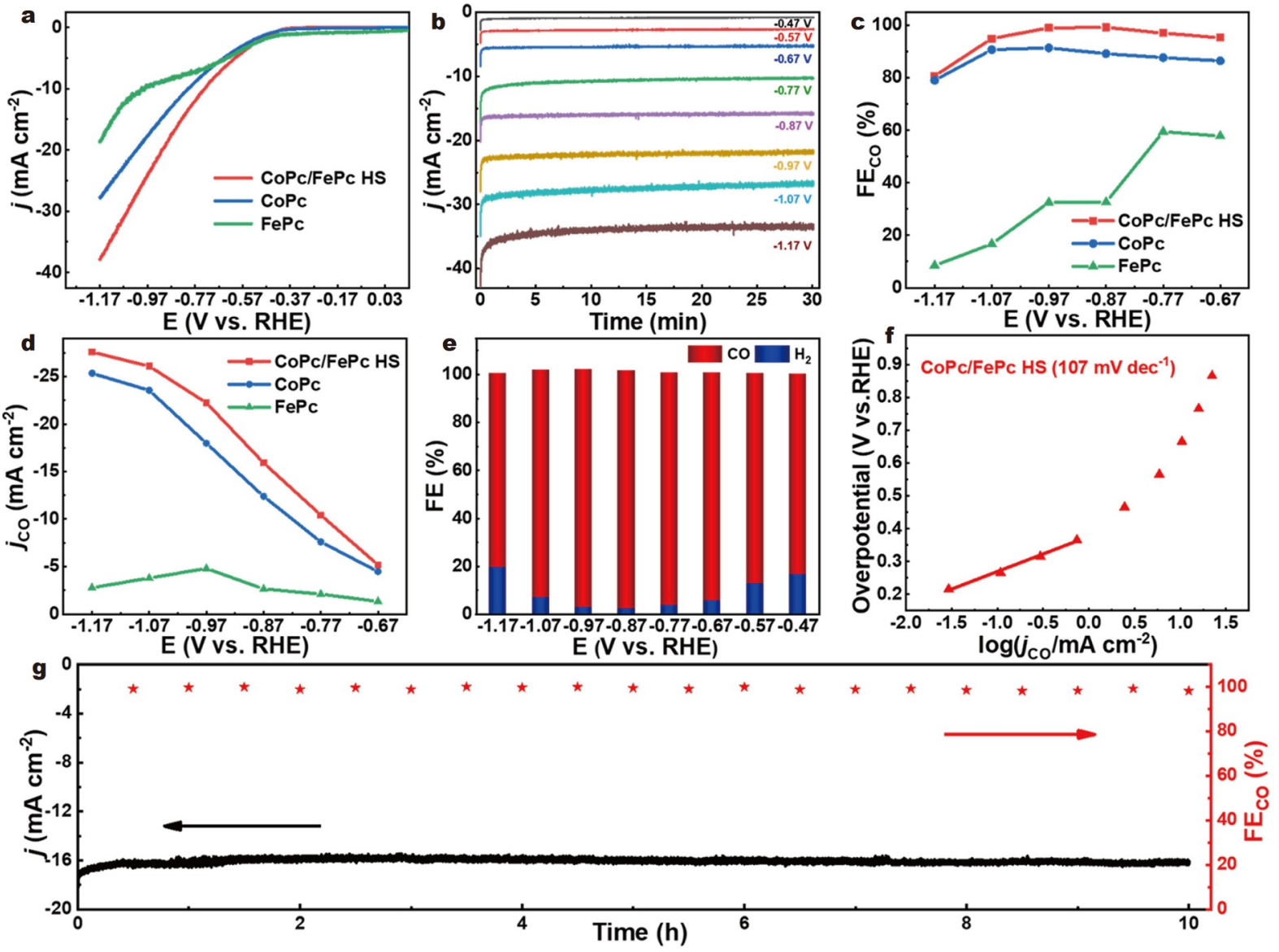

Figure 2 Electrochemical $\mathrm{CO}_{2} \mathrm{RR}$ performance of $\mathrm{CoPc} / \mathrm{FePc} \mathrm{HS}$. (a) LSV curves at $5 \mathrm{mV} \mathrm{s}^{-1}$ of FePc, CoPc, and CoPc/FePc HS. (b) CA measurements of $\mathrm{CoPc} / \mathrm{FePc} \mathrm{HS}$ at different fixed potentials. (c) $\mathrm{FE}_{\mathrm{CO}}$ and (d) $\mathrm{CO}$ partial current of $\mathrm{FePc}$, CoPc, and $\mathrm{CoPc} / \mathrm{FePc} \mathrm{HS}$ at different potentials in 0.5 mol $\mathrm{L}^{-1} \mathrm{KHCO}_{3}$ solution. (e) FEs of $\mathrm{CO}$ and $\mathrm{H}_{2}$ for $\mathrm{CoPc} / \mathrm{FePc} \mathrm{HS}$ in $0.5 \mathrm{~mol} \mathrm{~L}^{-1} \mathrm{KHCO}_{3}$ solution. (f) Tafel plots for $\mathrm{CoPc} / \mathrm{FePc} \mathrm{HS}$. (g) Stability measurement of CoPc/FePc HS at $-0.87 \mathrm{~V} v s$. RHE. 
respectively. The CA test was performed to evaluate the timedependent geometric current density of $\mathrm{CoPc} / \mathrm{FePc} \mathrm{HS}$ at different potentials ranging from -0.47 to $-1.17 \mathrm{~V} v s$. RHE (Fig. 2b). Notably, the CoPc/FePc HS shows excellent stability in $\mathrm{CO}_{2} \mathrm{RR}$ under the whole potential range. $\mathrm{CO}$ and $\mathrm{H}_{2}$ were the only reduction products determined using GC, and the presence of liquid products in the electrolyte was not detected by NMR. $\mathrm{CoPc} / \mathrm{FePc} \mathrm{HS}$ shows higher $\mathrm{FE}_{\mathrm{CO}}$ and the $\mathrm{CO}$ current density from -0.67 to $-1.17 \mathrm{~V} v s$. RHE compared with pure CoPc and FePc (Fig. 2c, d). By contrast, pure FePc and CoPc can only reduce $\mathrm{CO}_{2}$ into $\mathrm{CO}$ with low FEs of $32.63 \%$ and $89.19 \%$ at $-0.87 \mathrm{~V}$ vs. RHE, respectively. The $\mathrm{CoPc} / \mathrm{FePc} \mathrm{HS}$ produces CO with a maximum $\mathrm{FE}$ of $99.2 \%$ at $-0.87 \mathrm{~V}$ vs. RHE, with the $\mathrm{CO}$ current density of $15.9 \mathrm{~mA} \mathrm{~cm}^{-2}$ (Fig. 2e), which is superior to those given in the references listed in Table S1. In addition, we performed electrochemical tests on $\mathrm{CoPc} / \mathrm{FePc} \mathrm{HS}$ with different $\mathrm{Co} / \mathrm{Fe}$ content ratios of $3: 1,1: 1$, and 1:3 (Fig. S9). The FEs and current densities of $\mathrm{CoPc} / \mathrm{FePc} \mathrm{HS}(\mathrm{Co} / \mathrm{Fe}$ of $3: 1)$ are demonstrably superior to those of the samples with $\mathrm{Co} / \mathrm{Fe}$ ratios of $1: 1$ and $1: 3$ in the whole potential range of -0.67 to $-1.17 \mathrm{~V} v s$. RHE. We suspect that $\mathrm{Co}$ is the active site of $\mathrm{CoPc} / \mathrm{FePc} \mathrm{HS}$ in $\mathrm{CO}_{2} \mathrm{RR}$, and the reduction of Co sites results in a substantial decrease in the catalytic performance of the HS.

We obtained the Tafel slope of $\mathrm{CoPc} / \mathrm{FePc} \mathrm{HS}$ (Fig. 2f) to study the catalytic mechanism. According to the overpotentials of $0.22-0.37 \mathrm{~V}$, the $\mathrm{CoPc} / \mathrm{FePc} \mathrm{HS}$ presents a Tafel slope at approximately $107 \mathrm{mV} \mathrm{dec}^{-1}$, indicating that the $\mathrm{CO}_{2} \mathrm{RR}$ is kinetically limited and the formation of $\mathrm{CO}_{2}$ intermediate via one-electron transfer from $\mathrm{CoPc} / \mathrm{FePc} \mathrm{HS}$ to $\mathrm{CO}_{2}$ is the ratedetermining step. To better understand the intrinsic catalytic activity, the electrochemical active surface area of $\mathrm{CoPc} / \mathrm{FePc} \mathrm{HS}$ was estimated via the electrochemical double-layer capacitance $\left(C_{\mathrm{dl}}\right)$, which can be obtained through $\mathrm{CV}$ in a non-Faradaic region. The $C_{\mathrm{dl}}$ of $\mathrm{CoPc} / \mathrm{FePc} \mathrm{HS}$ was calculated to be $4.03 \mathrm{mF} \mathrm{cm}^{-2}$ (Fig. S10). We investigated the long-term stability of $\mathrm{CoPc} / \mathrm{FePc} \mathrm{HS}$. The FEs and current density show no significant loss at $-0.87 \mathrm{~V}$ vs. RHE over $10 \mathrm{~h}$ (Fig. $2 \mathrm{~g}$ ). The average $\mathrm{FE}_{\mathrm{CO}}$ reaches up to $99 \%$, and the average current density is $16 \mathrm{~mA} \mathrm{~cm}^{-2}$. The morphology and structure of $\mathrm{CoPc} / \mathrm{FePc} \mathrm{HS}$ were characterized via XRD and SEM to ensure the integrity of HS after the $\mathrm{CO}_{2} \mathrm{RR}$ test. The obtained XRD pattern is in accordance with that of a new one (Fig. S11). The SEM image (Fig. S12) shows that the morphology of the $\mathrm{CoPc} / \mathrm{FePc} \mathrm{HS}$ exhibits almost no change, indicating the excellent structural stability of HS.

DFT calculations were performed to reveal the origin of the $\mathrm{CO}_{2} \mathrm{RR}$ reactivity of $\mathrm{CoPc} / \mathrm{FePc} \mathrm{HS}$. The crystal and cluster models for $\mathrm{CoPc}, \mathrm{FePc}$, and $\mathrm{CoPc} / \mathrm{FePc} \mathrm{HS}$ are presented in Fig. 3a. Pure FePc and $\mathrm{CoPc}$ are semiconductors with band gaps of 0.28 and $0.61 \mathrm{eV}$, respectively, according to the PDOS analyses in Fig. 3b. The geometric optimizations for the crystal models of $\mathrm{FePc}$ and $\mathrm{CoPc}$ indicate their antiferromagnetic ground states and that the Fe atoms in FePc are in high spin states (Fig. 3c). Three double-layer cluster models were simulated as the reaction surfaces. The following catalytic pathway (Fig. 4a) was investigated, and the free energy diagrams (Fig. $4 \mathrm{~b}$ ) of $\mathrm{CO}_{2} \mathrm{RR}$ were estimated using the Nørskov equation $[63,64]$.

The adsorption of $\mathrm{CO}_{2}$ is an endothermic process with entropy reductions. The first electron transfer step from $\mathrm{CO}_{2}{ }^{*}$ to $\mathrm{COOH}^{*}$ is the rate-determining step, which is consistent with
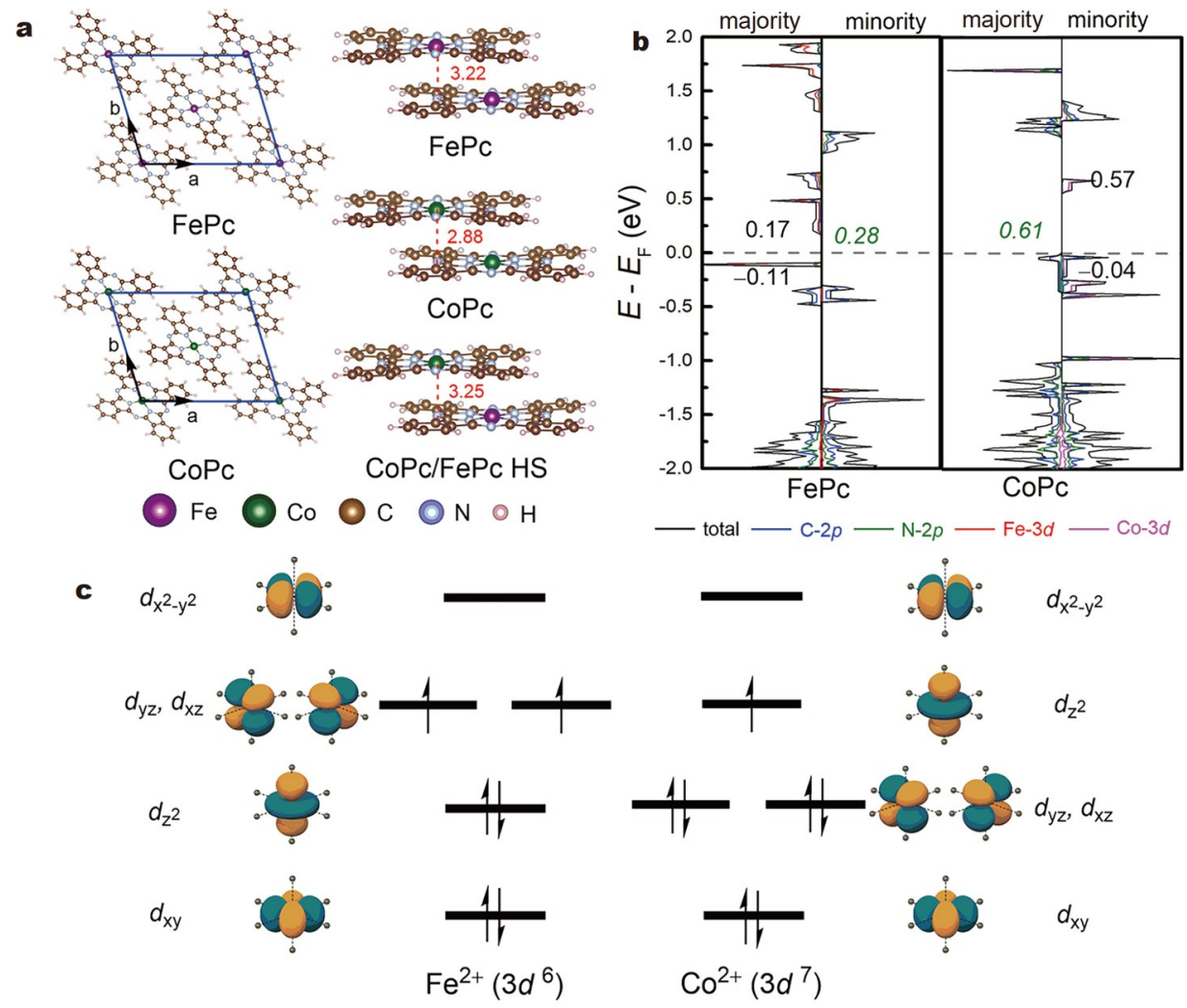

Figure 3 (a) Crystal and cluster models for FePc, CoPc, and CoPc/FePc HS. (b) Calculated PDOS for FePc and CoPc. (c) Valence 3d electron occupations on $\mathrm{Fe}$ and $\mathrm{Co}$ in the ground states of FePc and CoPc. 


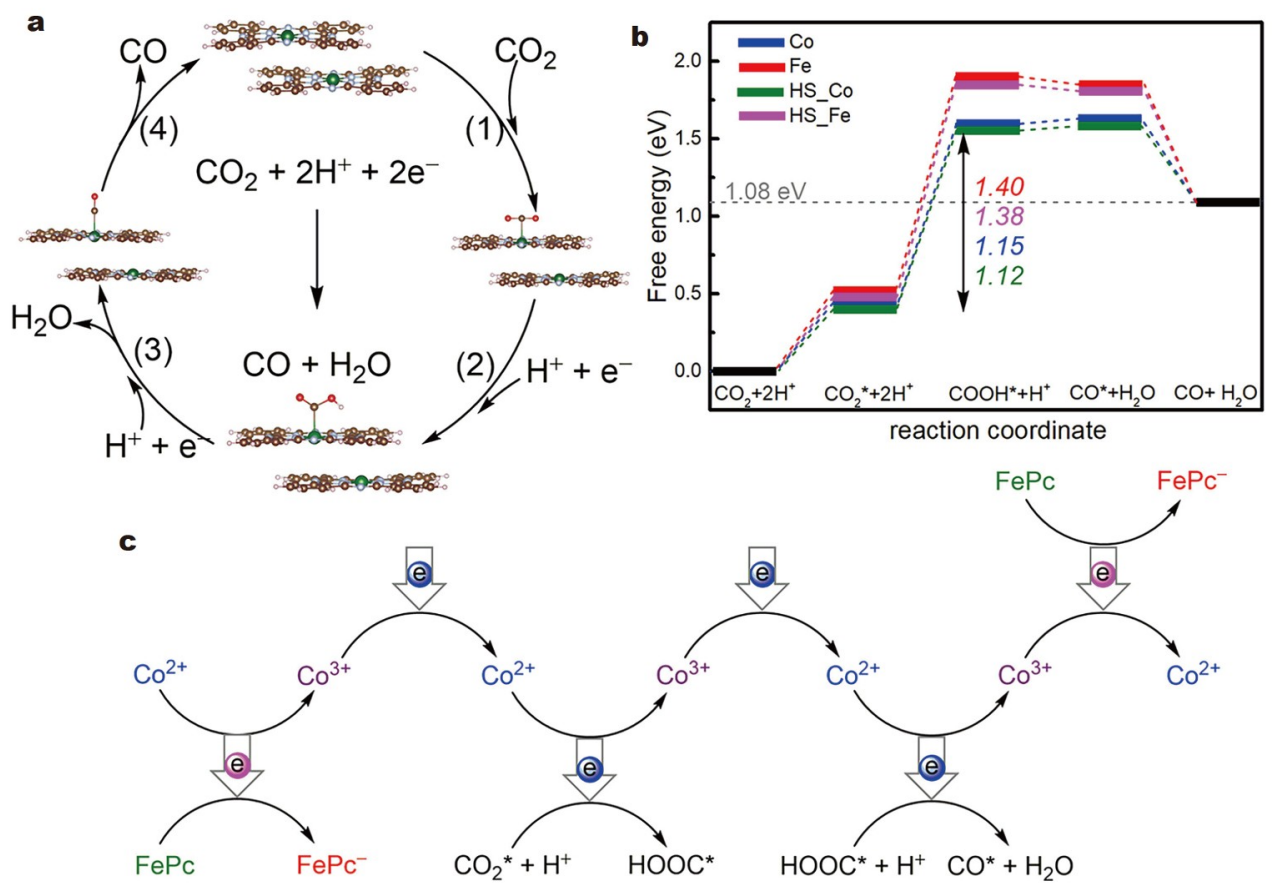

Figure 4 (a) Proposed mechanism for the electroreduction of $\mathrm{CO}_{2}$ to $\mathrm{CO}$ over $\mathrm{CoPc} / \mathrm{FePc} \mathrm{HS}$. (b) Calculated free energy profiles of $\mathrm{FePc}$, $\mathrm{CoPc}$, and $\mathrm{CoPc} /$ FePc HS. (c) Proposed electron transfer pattern for the high $\mathrm{CO}_{2} \mathrm{RR}$ activity of $\mathrm{CoPc} / \mathrm{FePc} \mathrm{HS}$.

the Tafel plot. The required free energy changes $(\Delta G)$ for FePc and $\mathrm{CoPc}$ are 1.40 and $1.15 \mathrm{eV}$, respectively, indicating a higher $\mathrm{CO}_{2} \mathrm{RR}$ activity of $\mathrm{CoPc}[65]$. The $\mathrm{CoPc} / \mathrm{FePc} \mathrm{HS}$ has Fe and $\mathrm{Co}$ atoms as two reaction centers, and the $\Delta G$ values are 1.38 and $1.12 \mathrm{eV}$, which are approximately equal to those of the pure $\mathrm{FePc}$ and $\mathrm{CoPc}$. This result indicates that the mutual influence between $\mathrm{Co}$ and $\mathrm{Fe}$ atoms is very limited in terms of local reactions. Moreover, the adsorption energies of $\mathrm{CO}_{2}(\mathrm{CO})$ on $\mathrm{FePc}$ and $\mathrm{CoPc}$ are $0.45(0.53) \mathrm{eV}$ and $0.51(0.76) \mathrm{eV}$, suggesting that $\mathrm{CO}_{2}$ and $\mathrm{CO}$ tend to desorb on CoPc. The enhancement of $\mathrm{CO}_{2} \mathrm{RR}$ activity can be explained by the electronic structures of $\mathrm{FePc}$ and $\mathrm{CoPc}$ and an electron transfer pattern at the HS (Fig. 4c). Electron transfer from CoPc to FePc occurs because CoPc exhibits a higher valence band maximum (VBM) of $-0.04 \mathrm{eV}$, whereas $\mathrm{FePc}$ exhibits a lower conduction band minimum $(\mathrm{CBM})$ of $0.17 \mathrm{eV}$. Thus, a $\mathrm{Co}^{3+}$ defect center is generated, and it delivers electrons from electrode to $\mathrm{CO}_{2}{ }^{*}$ and $\mathrm{COOH}^{*}$ step by step, forming the $\mathrm{Co}^{3+} / \mathrm{Co}^{2+}$ redox couple. The calculated band structure for $\mathrm{CoPc} / \mathrm{FePc} \mathrm{HS}$ in Fig. S13 indicates that the HS is a semiconductor with a direct band gap of $0.62 \mathrm{eV}$, which is larger than those of FePc $(0.28 \mathrm{eV})$ and CoPc $(0.61 \mathrm{eV})$. This phenomenon can be explained by charge density population analysis, suggesting that the VBM of the HS is mainly contributed by the $\mathrm{d}_{z}{ }^{2}\left(\mathrm{e}_{\mathrm{g}}\right)$ orbital of Co in CoPc, and the CBM is mainly contributed by the $\mathrm{d}_{x z} / \mathrm{d}_{y z}\left(\mathrm{t}_{2 \mathrm{~g}}\right)$ orbital of $\mathrm{Fe}$ in $\mathrm{FePc}$. The electron transfer from $t_{2 g}$ of $\mathrm{Fe}$ to the $\mathrm{e}_{\mathrm{g}}$ orbital of Co can decrease the energy of the $e_{g}$ band and increase the energy of the $t_{2 g}$ band, leading to its larger band gap. The above results indicate that an electron transfer occurs between the $\mathrm{CoPc}$ and $\mathrm{FePc}$ phases inside the $\mathrm{CoPc} / \mathrm{FePc} \mathrm{HS}$.

\section{CONCLUSION}

The molecular catalyst of $\mathrm{CoPc} / \mathrm{FePc} \mathrm{HS}$ exhibiting active interface, high crystallinity, and regulated composition was successfully prepared. The obtained $\mathrm{CoPc} / \mathrm{FePc} \mathrm{HS}$ with a $\mathrm{Co} / \mathrm{Fe}$ molar ratio of 3:1 exhibited 99\% $\mathrm{CO}_{2}$-to- $\mathrm{CO}$ conversion efficiency and outstanding stability. DFT calculations revealed that the enhancement of $\mathrm{CO}_{2} \mathrm{RR}$ activity could be attributed to the promoted rate-determining step of $\mathrm{CO}_{2} *$ to $\mathrm{COOH}^{*}$ induced by the electron transfer at the interface between CoPc and FePc. The HS engineering in molecular catalysts can inspire a unique approach for improving $\mathrm{CO}_{2} \mathrm{RR}$ performance.

Received 2 May 2021; accepted 23 June 2021;

published online 17 August 2021

1 Ross MB, De Luna P, Li Y, et al. Designing materials for electrochemical carbon dioxide recycling. Nat Catal, 2019, 2: 648-658

2 Wang L, Chen W, Zhang D, et al. Surface strategies for catalytic $\mathrm{CO}_{2}$ reduction: from two-dimensional materials to nanoclusters to single atoms. Chem Soc Rev, 2019, 48: 5310-5349

3 Nam DH, De Luna P, Rosas-Hernández A, et al. Molecular enhancement of heterogeneous $\mathrm{CO}_{2}$ reduction. Nat Mater, 2020, 19: 266-276

4 Ding M, Flaig RW, Jiang HL, et al. Carbon capture and conversion using metal-organic frameworks and MOF-based materials. Chem Soc Rev, 2019, 48: 2783-2828

5 Nitopi S, Bertheussen E, Scott SB, et al. Progress and perspectives of electrochemical $\mathrm{CO}_{2}$ reduction on copper in aqueous electrolyte. Chem Rev, 2019, 119: 7610-7672

6 Jiang X, Nie X, Guo X, et al. Recent advances in carbon dioxide hydrogenation to methanol via heterogeneous catalysis. Chem Rev, 2020, 120: 7984-8034

7 Daiyan R, Saputera WH, Masood H, et al. A disquisition on the active sites of heterogeneous catalysts for electrochemical reduction of $\mathrm{CO}_{2}$ to value-added chemicals and fuel. Adv Energy Mater, 2020, 10: 1902106

8 Zhang L, Zhao ZJ, Gong J. Nanostructured materials for heterogeneous electrocatalytic $\mathrm{CO}_{2}$ reduction and their related reaction mechanisms. Angew Chem Int Ed, 2017, 56: 11326-11353

9 Seh ZW, Kibsgaard J, Dickens CF, et al. Combining theory and ex- 
periment in electrocatalysis: Insights into materials design. Science, 2017, 355: eaad4998

10 Qiao J, Liu Y, Hong F, et al. A review of catalysts for the electroreduction of carbon dioxide to produce low-carbon fuels. Chem Soc Rev, 2014, 43: 631-675

11 Weng $\mathrm{Z}$, Jiang $\mathrm{J}, \mathrm{Wu} \mathrm{Y}$, et al. Electrochemical $\mathrm{CO}_{2}$ reduction to hydrocarbons on a heterogeneous molecular $\mathrm{Cu}$ catalyst in aqueous solution. J Am Chem Soc, 2016, 138: 8076-8079

12 Qin T, Qian Y, Zhang F, et al. Cloride-derived copper electrode for efficient electrochemical reduction of $\mathrm{CO}_{2}$ to ethylene. Chin Chem Lett, 2019, 30: 314-318

13 Wang N, Miao RK, Lee G, et al. Suppressing the liquid product crossover in electrochemical $\mathrm{CO}_{2}$ reduction. SmartMat, 2021, 2: 12-16

14 Chen Y, Li CW, Kanan MW. Aqueous $\mathrm{CO}_{2}$ reduction at very low overpotential on oxide-derived Au nanoparticles. J Am Chem Soc, 2012, 134: 19969-19972

$15 \mathrm{He} \mathrm{Q}$, Lee JH, Liu D, et al. Accelerating $\mathrm{CO}_{2}$ electroreduction to $\mathrm{CO}$ over Pd single-atom catalyst. Adv Funct Mater, 2020, 30: 2000407

16 García de Arquer FP, Dinh CT, Ozden A, et al. $\mathrm{CO}_{2}$ electrolysis to multicarbon products at activities greater than $1 \mathrm{~A} \mathrm{~cm}^{-2}$. Science, 2020, 367: 661-666

17 Zhang X, Wang Y, Gu M, et al. Molecular engineering of dispersed nickel phthalocyanines on carbon nanotubes for selective $\mathrm{CO}_{2}$ reduction. Nat Energy, 2020, 5: 684-692

18 Genovese C, Schuster ME, Gibson EK, et al. Operando spectroscopy study of the carbon dioxide electro-reduction by iron species on nitrogen-doped carbon. Nat Commun, 2018, 9: 935

19 Wang Y, Li Y, Wang Z, et al. Reticular chemistry in electrochemical carbon dioxide reduction. Sci China Mater, 2020, 63: 1113-1141

20 Costentin C, Drouet S, Robert M, et al. A local proton source enhances $\mathrm{CO}_{2}$ electroreduction to $\mathrm{CO}$ by a molecular Fe catalyst. Science, 2012, 338: 90-94

21 Lin S, Diercks CS, Zhang YB, et al. Covalent organic frameworks comprising cobalt porphyrins for catalytic $\mathrm{CO}_{2}$ reduction in water. Science, 2015, 349: 1208-1213

22 Yang $\mathrm{C}$, Li S, Zhang Z, et al. Organic-inorganic hybrid nanomaterials for electrocatalytic $\mathrm{CO}_{2}$ reduction. Small, 2020, 16: 2001847

23 Zhong $\mathrm{H}$, Zhang $\mathrm{Q}$, Wang J, et al. Engineering ultrathin $\mathrm{C}_{3} \mathrm{~N}_{4}$ quantum dots on graphene as a metal-free water reduction electrocatalyst. ACS Catal, 2018, 8: 3965-3970

24 Liu KH, Zhong HX, Li SJ, et al. Advanced catalysts for sustainable hydrogen generation and storage via hydrogen evolution and carbon dioxide/nitrogen reduction reactions. Prog Mater Sci, 2018, 92: 64-111

$25 \mathrm{Wu} \mathrm{Y,} \mathrm{Hu} \mathrm{G,} \mathrm{Rooney} \mathrm{CL,} \mathrm{et} \mathrm{al.} \mathrm{Heterogeneous} \mathrm{nature} \mathrm{of} \mathrm{electrocatalytic}$ $\mathrm{CO} / \mathrm{CO}_{2}$ reduction by cobalt phthalocyanines. ChemSusChem, 2020, cssc. 202001396

$26 \mathrm{Wu}$ J, Xie Y, Du S, et al. Heterophase engineering of $\mathrm{SnO}_{2} / \mathrm{Sn}_{3} \mathrm{O}_{4}$ drives enhanced carbon dioxide electrocatalytic reduction to formic acid. Sci China Mater, 2020, 63: 2314-2324

27 Lin L, Liu T, Xiao J, et al. Enhancing $\mathrm{CO}_{2}$ electroreduction to methane with a cobalt phthalocyanine and zinc-nitrogen-carbon tandem catalyst. Angew Chem Int Ed, 2020, 59: 22408-22413

28 Weng Z, Wu Y, Wang M, et al. Active sites of copper-complex catalytic materials for electrochemical carbon dioxide reduction. Nat Commun, 2018, 9: 415

29 Jiang Z, Wang Y, Zhang X, et al. Revealing the hidden performance of metal phthalocyanines for $\mathrm{CO}_{2}$ reduction electrocatalysis by hybridization with carbon nanotubes. Nano Res, 2019, 12: 2330-2334

30 Ren S, Joulié D, Salvatore D, et al. Molecular electrocatalysts can mediate fast, selective $\mathrm{CO}_{2}$ reduction in a flow cell. Science, 2019, 365: 367-369

31 Liu S, Yang HB, Hung SF, et al. Elucidating the electrocatalytic $\mathrm{CO}_{2}$ reduction reaction over a model single-atom nickel catalyst. Angew Chem Int Ed, 2020, 59: 798-803

32 Lin L, Li H, Yan C, et al. Synergistic catalysis over iron-nitrogen sites anchored with cobalt phthalocyanine for efficient $\mathrm{CO}_{2}$ electroreduction. Adv Mater, 2019, 31: 1903470

33 Kusama S, Saito T, Hashiba H, et al. Crystalline copper(II) phthalo- cyanine catalysts for electrochemical reduction of carbon dioxide in aqueous media. ACS Catal, 2017, 7: 8382-8385

34 Han N, Wang Y, Ma L, et al. Supported cobalt polyphthalocyanine for high-performance electrocatalytic $\mathrm{CO}_{2}$ reduction. Chem, 2017, 3: 652664

35 Gong S, Wang W, Xiao X, et al. Elucidating influence of the existence formation of anchored cobalt phthalocyanine on electrocatalytic $\mathrm{CO}_{2-}$ to-CO conversion. Nano Energy, 2021, 84: 105904

36 De Riccardis A, Lee M, Kazantsev RV, et al. Heterogenized pyridinesubstituted cobalt(II) phthalocyanine yields reduction of $\mathrm{CO}_{2}$ by tuning the electron affinity of the Co center. ACS Appl Mater Interfaces, 2020, 12: $5251-5258$

37 Zhang $\mathrm{X}$, Wu Z, Zhang $\mathrm{X}$, et al. Highly selective and active $\mathrm{CO}_{2}$ reduction electrocatalysts based on cobalt phthalocyanine/carbon nanotube hybrid structures. Nat Commun, 2017, 8: 14675

38 Ma Y, Li J, Liao X, et al. Heterostructure design in bimetallic phthalocyanine boosts oxygen reduction reaction activity and durability. Adv Funct Mater, 2020, 30: 2005000

39 Kresse G, Furthmüller J. Efficient iterative schemes for $a b$ initio totalenergy calculations using a plane-wave basis set. Phys Rev B, 1996, 54: 11169-11186

40 Blöchl PE. Projector augmented-wave method. Phys Rev B, 1994, 50 17953-17979

41 Perdew JP, Burke K, Ernzerhof M. Generalized gradient approximation made simple. Phys Rev Lett, 1996, 77: 3865-3868

42 Monkhorst HJ, Pack JD. Special points for Brillouin-zone integrations. Phys Rev B, 1976, 13: 5188-5192

43 Chen H, Shan H, Zhao A, et al. First-principles study of two dimensional transition metal phthalocyanine-based metal-organic frameworks in kagome lattice. Chin J Chem Phys, 2019, 32: 563-571

44 Grimme S, Ehrlich S, Goerigk L. Effect of the damping function in dispersion corrected density functional theory. J Comput Chem, 2011, 32: $1456-1465$

45 Liang W, Chen J, Liu Y, et al. Density-functional-theory calculation analysis of active sites for four-electron reduction of $\mathrm{O}_{2}$ on $\mathrm{Fe} / \mathrm{N}$-doped graphene. ACS Catal, 2014, 4: 4170-4177

$46 \mathrm{Wu} \mathrm{Y}$, Jiang $\mathrm{Z}, \mathrm{Lu} \mathrm{X}$, et al. Domino electroreduction of $\mathrm{CO}_{2}$ to methanol on a molecular catalyst. Nature, 2019, 575: 639-642

47 Gajda $Ł$, Kupka T, Małolepszy A, et al. Spectroscopic characterization of non-covalent $\mathrm{CuPc}-\mathrm{GO}$ system. Experiment and theory. Mater Chem Phys, 2019, 231: 301-310

48 Verma D, Dash R, Katti KS, et al. Role of coordinated metal ions on the orientation of phthalocyanine based coatings. SpectroChim Acta Part A-Mol Biomol Spectr, 2008, 70: 1180-1186

49 Latiff NM, Fu X, Mohamed DK, et al. Carbon based copper(II) phthalocyanine catalysts for electrochemical $\mathrm{CO}_{2}$ reduction: Effect of carbon support on electrocatalytic activity. Carbon, 2020, 168: 245-253

50 Sonkar PK, Ganesan V, Gupta R, et al. Nickel phthalocyanine integrated graphene architecture as bifunctional electrocatalyst for $\mathrm{CO}_{2}$ and $\mathrm{O}_{2}$ reductions. J Electroanal Chem, 2018, 826: 1-9

51 Ma DD, Han SG, Cao C, et al. Bifunctional single-molecular heterojunction enables completely selective $\mathrm{CO}_{2}$-to-CO conversion integrated with oxidative 3D nano-polymerization. Energy Environ Sci, 2021, 14: 1544-1552

52 Sun L, Reddu V, Fisher AC, et al. Electrocatalytic reduction of carbon dioxide: Opportunities with heterogeneous molecular catalysts. Energy Environ Sci, 2020, 13: 374-403

53 Meng F, Zhong $\mathrm{H}$, Bao D, et al. In situ coupling of strung $\mathrm{Co}_{4} \mathrm{~N}$ and intertwined $\mathrm{N}-\mathrm{C}$ fibers toward free-standing bifunctional cathode for robust, efficient, and flexible Zn-air batteries. J Am Chem Soc, 2016, 138: 10226-10231

54 Zhong $\mathrm{H}$, Liu K, Zhang Q, et al. Copper tetrazolate based metal-organic frameworks as highly efficient catalysts for artificially chemical and electrochemical $\mathrm{CO}_{2}$ conversion. Nano Sel, 2020, 1: 311-319

55 Choi J, Wagner P, Gambhir S, et al. Steric modification of a cobalt phthalocyanine/graphene catalyst to give enhanced and stable electrochemical $\mathrm{CO}_{2}$ reduction to CO. ACS Energy Lett, 2019, 4: 666-672

56 Wang J, Wang G, Zhang J, et al. Inversely tuning the $\mathrm{CO}_{2}$ electro- 
reduction and hydrogen evolution activity on metal oxide via heteroatom doping. Angew Chem Int Ed, 2021, 60: 7602-7606

57 Zhu M, Chen J, Huang L, et al. Covalently grafting cobalt porphyrin onto carbon nanotubes for efficient $\mathrm{CO}_{2}$ electroreduction. Angew Chem Int Ed, 2019, 58: 6595-6599

58 Chen J, Zhu M, Li J, et al. Structure-activity relationship of the polymerized cobalt phthalocyanines for electrocatalytic carbon dioxide reduction. J Phys Chem C, 2020, 124: 16501-16507

59 Huai $\mathrm{M}$, Yin Z, Wei F, et al. Electrochemical $\mathrm{CO}_{2}$ reduction on heterogeneous cobalt phthalocyanine catalysts with different carbon supports. Chem Phys Lett, 2020, 754: 137655

$60 \mathrm{Ju} \mathrm{W}$, Bagger A, Wang $\mathrm{X}$, et al. Unraveling mechanistic reaction pathways of the electrochemical $\mathrm{CO}_{2}$ reduction on $\mathrm{Fe}-\mathrm{N}-\mathrm{C}$ single-site catalysts. ACS Energy Lett, 2019, 4: 1663-1671

61 Xu F, Zhang L, Ding X, et al. Selective electroreduction of dinitrogen to ammonia on a molecular iron phthalocyanine/O-MWCNT catalyst under ambient conditions. Chem Commun, 2019, 55: 14111-14114

62 Li X, Rong H, Zhang J, et al. Modulating the local coordination environment of single-atom catalysts for enhanced catalytic performance. Nano Res, 2020, 13: 1842-1855

63 Nørskov JK, Rossmeisl J, Logadottir A, et al. Origin of the overpotential for oxygen reduction at a fuel-cell cathode. J Phys Chem B, 2004, 108: 17886-17892

$64 \mathrm{Xu} \mathrm{H}$, Cheng D, Cao D, et al. A universal principle for a rational design of single-atom electrocatalysts. Nat Catal, 2018, 1: 339-348

65 Pan Y, Lin R, Chen Y, et al. Design of single-atom Co- $\mathrm{N}_{5}$ catalytic site: A robust electrocatalyst for $\mathrm{CO}_{2}$ reduction with nearly $100 \% \mathrm{CO}$ selectivity and remarkable stability. J Am Chem Soc, 2018, 140: 42184221

Acknowledgements This work was supported by the National Natural Science Foundation of China $(22071172,91833306,21875158,51633006$, and 51733004).

Author contributions Zhang Z, Gao XJ, and $\mathrm{Hu}$ W conceived and supervised this study; Yang C, Gao Z, Zhang Z, and Gao XJ wrote the paper; $\mathrm{Li}$ $\mathrm{S}$, Li J, Zhu Y, and Wang $\mathrm{H}$ carried out the materials fabrication, characterizations, and electrochemical measurements; Wang D, Yang W, and Gao XJ performed the DFT calculations and computational models; All authors contributed to discussions and manuscript review.

Conflict of interest The authors declare no conflict of interest.

Supplementary information Supporting data are available in the online version of the paper.

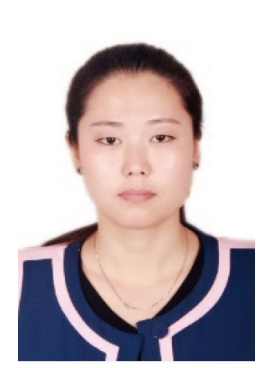

Xuejiao J. Gao received her $\mathrm{PhD}$ degree from the School of Chemistry and Chemical Engineering, University of Chinese Academy of Sciences (Beijing) in 2017. Then, she joined the College of Chemistry and Chemical Engineering, Jiangxi Normal University as an associate professor. Her research interests focus on surface and interface chemistry of nanomaterials and its application in biomimetic catalysis.

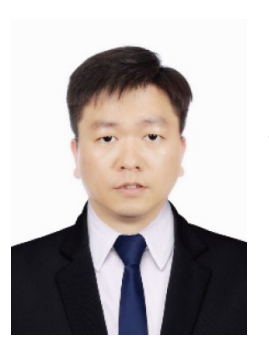

Zhicheng Zhang is a Professor of Tianjin University, China. He obtained his $\mathrm{PhD}$ degree from China University of Petroleum (Beijing) in 2012. Then he joined Tsinghua University as a postdoctoral researcher. In 2014, he worked as a research fellow at Nanyang Technological University, Singapore. In 2019, he joined Tianjin University as a full Professor. His research interests focus on the design and synthesis of functional metal-based nanomaterials and their applications in energy conversion and catalysis.

\section{双金属酞菁异质结构高选择性电催化 $\mathrm{CO}_{2}$ 还原}

杨宸槐 ${ }^{1 \dagger}$, 高增强 ${ }^{1 \dagger}$, 王定佳 ${ }^{2 \dagger}$, 李舒豫 ${ }^{1}$, 李俊俊 ${ }^{1}$, 朱亚廷 $^{1}$, 王海青 ${ }^{3}$, 杨文娟 ${ }^{4}$, 高雪娇 ${ }^{2}$, 张志成 ${ }^{1 *}$, 胡文平 ${ }^{1}$

摘要 自工业革命以来, 化石燃料的大量消耗导致大气中 $\mathrm{CO}_{2}$ 浓度显著 增加, 引发了全球气候变暖等问题. 电化学 $\mathrm{CO}_{2}$ 还原能够利用可再生能 源产生的间歇性电力可持续地将 $\mathrm{CO}_{2}$ 转化为高附加值化学品或燃料, 是 实现碳中和的有效途径. 目前, 非均相分子催化剂如金属酞菁能够有效 催化 $\mathrm{CO}_{2}$ 还原反应 $\left(\mathrm{CO}_{2} \mathrm{RR}\right)$, 但是分子催化剂异质结构的合理设计与合 成仍极具挑战. 基于此, 我们发展了一种具有高结晶度的双金属酞菁异 质结构 $(\mathrm{CoPc} / \mathrm{FePc} \mathrm{HS})$, 其电催化 $\mathrm{CO}_{2}$ 还原为 $\mathrm{CO}$ 的法拉第效率高达 99\%, 并在运行10小时后性能基本保持不变. 密度泛函理论计算表明, $\mathrm{FePc}$ 和 CoPc之间不同的电子转移模式能够有效提高 $\mathrm{CO}_{2} \mathrm{RR}$ 性能. 构筑 分子催化剂异质结构有望成为 $\mathrm{CO}_{2} \mathrm{RR}$ 性能提升的有效策略. 